\title{
Political Competition in Weak States
}

\section{Citation}

La Ferrara, Eliana, and Robert H. Bates. 2001. Political competition in weak states. Economics \& Politics 13(2): 159-184.

\section{Published Version}

http://dx.doi.org/10.1111/1468-0343.00088

\section{Permanent link}

http://nrs.harvard.edu/urn-3:HUL.InstRepos:3224415

\section{Terms of Use}

This article was downloaded from Harvard University's DASH repository, and is made available under the terms and conditions applicable to Other Posted Material, as set forth at http:// nrs.harvard.edu/urn-3:HUL.InstRepos:dash.current.terms-of-use\#LAA

\section{Share Your Story}

The Harvard community has made this article openly available.

Please share how this access benefits you. Submit a story.

Accessibility 


\title{
Political Competition in Weak States
}

\author{
Eliana LaFerrara and Robert H. Bates
}

CID Working Paper No. 68

June 2001

(C) Copyright 2001 Eliana LaFerrara and Robert H. Bates and the

President and Fellows of Harvard College

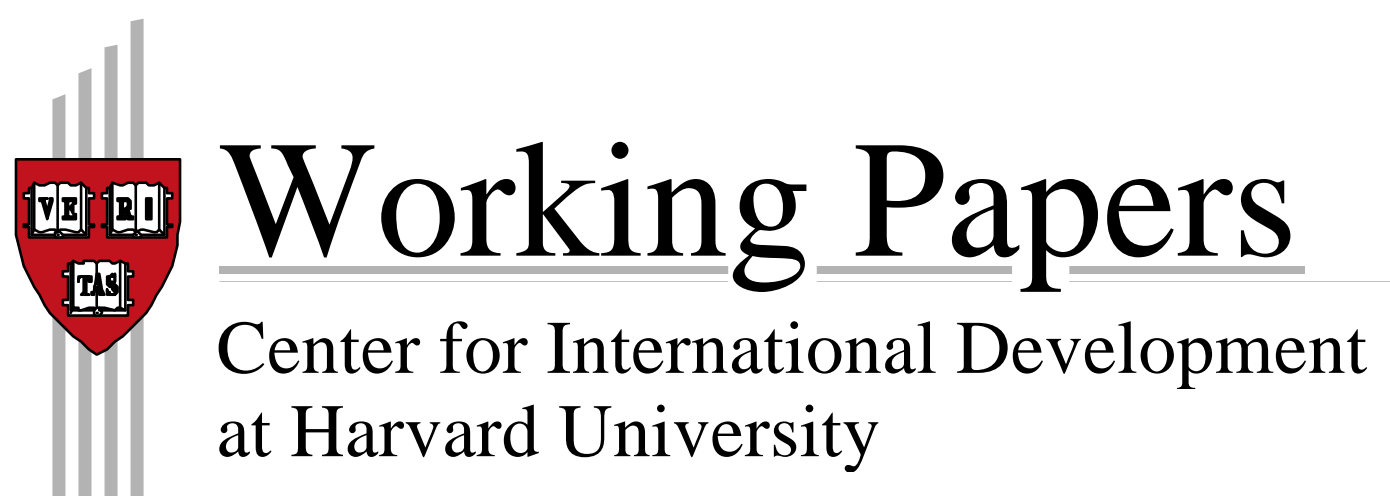




\title{
Political Competition in Weak States
}

\author{
Eliana LaFerrara and Robert H. Bates
}

\begin{abstract}
In less developed societies, states are weak, possessing no monopoly over violence, and political competition is not constrained by the rules of election. The paper presents and analyzes a simple model of political competition in such settings. Citizens are viewed as occupying fixed locations; they cannot choose whether to participate, i.e. to pay taxes, but can choose which politician to support. Politicians are viewed as seeking wealth, which they pursue by recruiting political followers. They campaign for supporters by providing local public goods, by recruiting armed followers, and by playing upon cultural identities. Within this framework, we ask: Choosing optimally, how will politicians behave? What factors yield political advantages? How do cultural identities shape political competition and political violence? What are the implications for peace keeping in developing nations?
\end{abstract}

Keywords: rent seeking, conflict, local public goods, political competititon.

JEL Codes: D72, D74, H41, O23

Eliana LaFerrara is a graduate of the Department of Economics at Harvard University. She currently holds appointments at the Universita' Bocconi and IGIER, Milan, Italy.

Robert H. Bates is the Eaton Professor of the Science of Government and Faculty Fellow at the Center for International Development at Harvard University. 


\section{Introduction}

Since the seminal contribution of Downs (1957), the theory of political competition in advanced industrial democracies has developed rapidly; it now constitutes a mature branch of scholarship (e.g., Enelow and Hinich (1984), Persson and Tabellini (2000)). While there exists a voluminous literature on politics in developing societies (e. g., Almond and Coleman (1960), Anderson, von der Mehden and Young (1967), Huntington (1968)), few efforts have been made to develop a theory of political competition based upon the distinctive properties of underdeveloped states. The formal analysis of politics in the developing areas therefore remains less advanced than that of the politics in the advanced industrial democracies.

In an effort to address this hortcoming, we develop in this article a model of political competition that seeks to capture important characteristics of political competition in underdeveloped polities. These characteristics include:

1. That the state is weak (Evans, Skocpol, and Rueschmeyer (1985); Evans (1995); Myrdal, Kohli, and Shu (1994)). That is, the state lacks a monopoly over the use of violence (Weber (1958)); the use of coercion is controlled by political élites.

2. That democratic institutions are weak. Political competition is not governed by the rules of elections.

3. That politicians compete for private rents, extracted from public revenues (Marcouiller and Young (1995)).

4. That politics is "personalistic". Because of charisma (Apter (1963)); a tradition of "big man" politics (Jackson and Rosberg (1982)); or the forces of cultural identity (Geertz (1963)), personal characteristics can be as important as issue stands in determining the appeal of politicians.

To analyze political competition in political settings that share these characteristics, we develop a simple model of political competition in which two politicians compete to recruit tax-paying citizens into their respective political camps. Citizens are viewed as occupying fixed locations and politicians strive to provide local public goods, the value of which declines with distance. They also mobilize military force; security is treated as a pure public good, the value of which does not decline 
with distance. Citizens must participate, i.e. pay taxes; but they can choose which leader to support. Citizens are attracted to the leader who provides a higher level of security or more valuable public goods or whose personal attributes they find the more attractive. We first model personal attributes as unvarying (i.e. as valences) and then as a parameter that varies across individuals in a manner consistent with regional or ethnic preferences. The political competitors seek to maximize rents. But to secure revenues, they must incur the costs of providing carrots (i.e. the local public goods) or sticks (i.e. military forces) in order to build a tax-paying following.

The issues we then address are:

a. Behaving optimally, how will the political leaders choose? What mix of public goods and military expenditure will they choose?

b. What factors yield significant political advantages? What determines who is more likely to win?

c. What is the role of cultural variables and political identities in such settings?

d. What are the implications for intervention in peace keeping efforts in developing nations?

In Section 2, we briefly review some related literature and discuss how it compares to our approach. In Section 3, we introduce the basic model. In Section 4, we explore the properties of different types of equilibria, and thereby characterize political behavior in a variety of settings. In Sections 5 to 7, we explore extensions of the model. In Section 5 and 6, we alter our characterization of the impact of the military; and in an effort to capture the impact of ethnic loyalty, in Section 7 we alter our characterization of the attributes of competitors, enabling us to explore the political role of cultural identities. In section 8 we provide some empirical illustrations. 


\section{Background}

Recent papers by Hirshleifer (1991), Skaperdas (1992), Grossman and Kim (1995) and Grossman (1997) explore the relationship between defense, predation and investment in productive activities when property rights are insecure. These papers focus on the resources diverted from directly productive activities to the defense of property rights. While recognizing the importance of these issues, in this paper we abstract from them in order to concentrate on the choices between military expenditure and public good provision by rival politicians, taking as given the allocation of productive resources by the citizens. In particular, we assume that property rights are clearly defined and enforceable, and that military expenditures are made to increase the size of the political constituency.

Ellman and Wantchekon (2000) examine the effects of violence on political competition in a two party system. In their model, candidates compete in elections and seek votes. Violence takes place after the period of political competition. In our model, there are no elections. Élites seek popular support in order to secure public revenues. And while Ellman and Wantchekon consider the threat of violence as a means of securing leverage over public policy, we treat military force as a means of consolidating a political constituency. As a result, in our model, positive quantities of military expenditures may be chosen by players in equilibrium.

Our model is probably closer in spirit to that of Marcouiller and Young (1995), who study the problem faced by an incumbent who maximizes rents from power by choosing the tax rates to which citizens are subject and the public services they receive. The citizens, on their part, can opt between paying taxes to the incumbent or entering the informal sector. In this paper, we do not allow citizens to opt out (everyone must pay taxes in our model) and we concentrate on the competition between two rent-maximizing candidates, exploring the role of cultural and ethnic attributes of the candidates in shaping political competition. Also, we allow military expenditure to affect the terms of such competition, while Marcouiller and Young do not.

The specification of our model resembles that of Alesina and Spolaore (1997) and Collier and Hoeffler (1998). We focus, however, on the impact of preference heterogeneity upon the 
behavior of competing political élites rather than upon the optimal size of the political community. The specification also resembles that of Enelow and Hinich (1982) and Harrington and Hess (1996), in that it stresses the political significance of the candidates' characteristics as well as their policy positions. In our model, however, the politicians expand the size of their coalition in order to increase the magnitude of their revenues, rather than the number of votes. Moreover, they can choose coercion as well as spatial location in their search for public backing.

\section{A Simple Model}

We present a model in which citizens are distributed uniformly along a single dimension that runs along the unit interval $[0,1]$. The dimension can be conceived as suggesting differences in location or space (Alesina and Spolaore (1997)).

\section{The competitors:}

There are two competitors, $\mathrm{A}$ and $\mathrm{B}$ : $\mathrm{A}$ is located at point 0 and $\mathrm{B}$ at point 1 . Each competes for supporters from which they levy taxes, $t$ per person.

To bid for support, each competitor provides a costly local public good: competitor A locates her public good at $\lambda_{A} \in[0,1]$ and her rival locates it at $\lambda_{B} \in[0,1]$. The amount of public good provided is assumed to be fixed and equal for both; the cost of providing the good varies, however, depending on location. We denote A's cost of locating the public good at $\lambda_{A}$ by $C\left(\lambda_{A}\right)$ and B's cost of locating at $\lambda_{B}$ by $c\left(\lambda_{B}\right)$. We assume that the further the good is from endpoint 0 (1) the costlier it is for competitor A (B) to provide. A possible interpretation is that the two competitors are located in their respective "capitals" or "bases", 0 and 1, and transport or monitoring costs make the good more difficult to provide or to finance the greater the distance from the political center. In particular we assume: ${ }^{1}$

\footnotetext{
${ }^{1}$ Notice the asymmetry in the sign of the first derivatives: as $\lambda_{A}$ increases, the costs of player A increase, while the costs to player $B$ are lower the larger $\lambda_{B}$ (i.e., the closer $\lambda_{B}$ is to 1 ). In both cases, the second derivatives say that a player's costs increase at a non-decreasing rate with the distance of the public good from the player's "base".
} 


$$
\begin{aligned}
& C^{\prime}\left(\boldsymbol{\lambda}_{A}\right)>0, C^{\prime \prime}\left(\lambda_{A}\right) \geq 0 \\
& c^{\prime}\left(\lambda_{B}\right)<0, c^{\prime \prime}\left(\lambda_{B}\right) \geq 0
\end{aligned}
$$

To enhance its support, each player also spends resources on military equipment: $M$, for competitor A, $m$ for $\mathrm{B}$, where $M, m \geq 0$. The costs to $\mathrm{A}$ and $\mathrm{B}$ from buying quantities $M$ and $m$ of arms are given, respectively, by the functions $H(M)$ and $h(m)$, with the characteristics: ${ }^{2}$

$$
\begin{aligned}
H^{\prime}(M) & >0, H^{\prime \prime}(M)>0 \\
h^{\prime}(m) & >0, h^{\prime \prime}(m)>0
\end{aligned}
$$

The timing of the game is the following. In period 1, the competitors $\mathrm{A}$ and $\mathrm{B}$ simultaneously ${ }^{3}$ choose a combination of public good provision and military expenditure, $\left(\lambda_{A}, M\right)$ and $\left(\lambda_{B}, m\right)$, respectively. In period 2 , each citizen decides whether to pay taxes to A or to B. In the first instance the citizen "consumes" the bundle $\left(\lambda_{A}, M\right)$, in the second $\left(\lambda_{B}, m\right)$. After taxes are collected and the public goods are consumed, the game ends. For simplicity, we assume that players do not discount utility across time.

Two points are worth stressing regarding the structure of the game. First, individuals cannot relocate on the unit line: in this sense, our model is not one in which individuals "vote with their feet". Nor can individuals opt out by refusing to pay taxes. What each individual can choose is whom to support financially and politically and whose public good to consume. Addressing free riding and enforcement problems is not among the goals of this paper; hence we assume that every citizen has to pay taxes to one of the competitors, be it A or B. In particular, we assume that both competitors collect a lump sum payment $t$ from every individual in their constituency.

Let the size of A's and B's constituency be $x\left(\lambda_{A}, \lambda_{B}, M, m\right)$ and $1-x\left(\lambda_{A}, \lambda_{B}, M, m\right)$, respectively. Leaving aside for the moment our derivation of $x\left(\lambda_{A}, \lambda_{B}, M, m\right)$, the problem for A becomes:

\footnotetext{
${ }^{2}$ Notice that military expenditure does not have a spatial dimension in this model. In fact, we assume that military costs depend on the total amount of personnel/equipment bought, and not on the distance between the capital and some other location. Our framework thus differentiates between a public good whose provision costs rise with the distance $\left(\lambda_{A}, \lambda_{B}\right)$ and one whose provision costs rise with quantity $(M, m)$.
} 


$$
\begin{array}{ll}
\max _{\lambda_{A}, M} & \operatorname{tx}\left(\lambda_{A}, \lambda_{B}, M, m\right)-C\left(\lambda_{A}\right)-H(M) \\
\text { s.t. } & t x\left(\lambda_{A}, \lambda_{B}, M, m\right)-C\left(\lambda_{A}\right)-H(M) \geq 0 \\
& 0 \leq \lambda_{A} \leq 1, \quad M \geq 0 .
\end{array}
$$

Competitor B solves an analogous problem:

$$
\begin{array}{ll}
\max _{\lambda_{B}, m} & t\left[1-x\left(\lambda_{A}, \lambda_{B}, M, m\right)\right]-c\left(\lambda_{B}\right)-h(m) \\
\text { s.t. } & t\left[1-x\left(\lambda_{A}, \lambda_{B}, M, m\right)\right]-c\left(\lambda_{B}\right)-h(m) \geq 0 \\
& 0 \leq \lambda_{B} \leq 1, \quad m \geq 0 .
\end{array}
$$

The objective function for both players is the excess of tax revenue over the costs, i.e. the net "rents" that they receive. ${ }^{4}$ In this sense, each competitor is "predatory" with respect to its constituency. The only reason why the competitors spend on public goods and/or on military equipment is that, by securing political support, they also secure public revenues. The first constraint in each optimization problem requires that the competitor does not run deficits; we assume that if this constraint is violated, the player quits the game. We call the combinations $\left(\lambda_{A}, \lambda_{B}, M, m\right)$ that satisfy these constraints "feasible".

\section{The Citizens:}

The citizens are distributed uniformly on the interval [0,1], and each of them is indexed by her location, $l$. We define the utility that a citizen located at $l$ derives from supporting $\mathrm{A}$ or $\mathrm{B}$, respectively, as: ${ }^{5}$

\footnotetext{
${ }^{3}$ Our equilibrium concept is therefore that of Nash equilibrium. For analytical simplicity and to represent a situation in which elites compete on the same grounds, we chose not to model the game as a sequential game.

${ }^{4}$ A possible extension of the model is to make the tax rate endogenous. Abstracting from the choice of the tax rate allows to concentrate on the trade-offs between $\lambda_{\mathrm{A}}$ and $M$, and between $\lambda_{\mathrm{B}}$ and $m$, which are the focus of this paper.

5 Notice that if the lump sum tax $t$ entered citizens' utility it would just shift it by a constant: $t$ is in fact exogenous and it has to be paid to either one of the competitors. For this reason, we choose to economize on notation and omit it from (3) and (4).
} 


$$
\begin{aligned}
& U(l, A) \equiv \alpha_{A}-V\left(\left|l-\lambda_{A}\right|\right)-g(m) \\
& U(l, B) \equiv \alpha_{B}-V\left(\left|l-\lambda_{B}\right|\right)-G(M)
\end{aligned}
$$

Each citizen's utility is thus a function of three arguments:

(i) Some (unalterable) attributes of the rulers, which we denote by $\alpha_{A}$ for player $A$ and $\alpha_{B}$ for the rival. For the moment, we assume that this "valence" index does not vary with location and that, without loss of generality: ${ }^{6}$

(A3)

$$
\alpha_{A}>\alpha_{B}
$$

This assumption will be relaxed in section 7 and the parameters $\alpha_{A}$ and $\alpha_{B}$ will be allowed to differ among citizens depending on their location.

(ii) The distance of the citizen from the public good: the greater this distance, the lower the utility the public good provides. Because people like to have the public good located as close as possible, we represent the geographical distribution of the population as the distribution of ideal points for $\lambda_{i}$. Any discrepancy between the ideal point $l$ and the actual location $\lambda_{i}$ reduces individual $l$ 's utility according to the function $V\left(\left|l-\lambda_{i}\right|\right)$, which is assumed to be increasing and convex:

$$
V^{\prime}(\cdot)>0, V^{\prime \prime}(\cdot)>0 \text {. }
$$

We normalize $V(0)$ to equal zero. Notice that only one public good enters $V(\cdot)$ because the citizens are assumed to consume either the good provided by A or that provided by B. ${ }^{7}$

(iii) The military strength of the two competitors: a citizen's utility from supporting a competitor decreases with the amount spent in military force by its opponent. Our specification, where A's and B's military capabilities enter the utility of the public additively through the functions $G(M)$ and $g(m)$, suggests that military capabilities are a "bad". What matters for the equilibrium is

\footnotetext{
6 Whatever conclusion we draw on competitor A based on assumption (A3) could equally be applied to the opponent in case he or she had a higher "valence" index.

7 As an example, we can think of a choice between schools: people cannot send their children to a different school everyday.
} 
only the relative amount of military expenditure by the two competitors, as will be clear in the following section. ${ }^{8}$ We assume that there are positive but decreasing returns to military force:

$$
\begin{aligned}
& G^{\prime}(\cdot)>0, G^{\prime \prime}(\cdot)<0, G(0)=0 \\
& g^{\prime}(\cdot)>0, g^{\prime \prime}(\cdot)<0, g(0)=0
\end{aligned}
$$

We will experiment with different specifications of the technology of conflict. In section 5 we will introduce relative military capabilities in the form of differences or ratio. In section 6 we will allow military expenditure to provide a complement to, rather than a substitute for, public good provision. The interpretation in this case will be that defense enhances the satisfaction derived from public services, e.g. by making it less dangerous to gain access to them.

\section{The Argument}

To analyze the behavior of the competitors in equilibrium, we first define citizen $x$, who is indifferent between them. Figure 1 depicts the utility that citizens in $[0,1]$ receive from supporting the two competitors when A locates the public good at $\lambda_{A}$ and B at $\lambda_{B}$ (for given $M$ and $m$ ). ${ }^{9}$

\section{[Insert figure 1]}

The citizen $x$, located at the intersection of the two inverted- $U$ curves, is indifferent between contributing to A or to B. Lemma 1 gives sufficient conditions for the existence of $x$ and defines it analytically.

Lemma 1: For each feasible combination $\left(\lambda_{A}, \lambda_{B}, M, m\right)$ such that $0 \leq \lambda_{A}<\lambda_{B} \leq 1$, and

$$
-V\left(\lambda_{B}-\lambda_{A}\right)<\alpha_{A}-\alpha_{B}+G(M)-g(m)<V\left(\lambda_{B}-\lambda_{A}\right)
$$

there exists a $x \in\left(\lambda_{A}, \lambda_{B}\right)$ such that individuals in the segment $[0, x)$ will support competitor A, individuals in the segment $(x, 1]$ will support $\mathrm{B}$, and individual $x$ will be indifferent between the two. The "marginal supporter" $x$ is defined by:

$$
\alpha_{A}-V\left(x-\lambda_{A}\right)-g(m)=\alpha_{B}-V\left(\lambda_{B}-x\right)-G(M) .
$$

\footnotetext{
${ }^{8}$ In terms of figures 1-3 below, the role of these functions is to induce a relative shift in the utility curves for the two competitors, and all we are interested in is the impact that such shift has on the intersection point that identifies the "marginal" citizen.
} 
Proof: see the appendix.

Assumption (A6) requires that a citizen located exactly at $\lambda_{A}$ receives higher utility from $A$ than $B$, and that a citizen located at $\lambda_{B}$ gets higher utility from B than A. If (A6) were violated, all citizens might prefer one competitor to the other; we wish to rule this situation out because, for present purposes, it is uninteresting. Intuitively, (A6) guarantees that the "valence advantage" and military force of a competitor are not so big to offset the "location advantage" of the rival in the place where the latter locates the public good.

It follows from lemma 1 that the size of A's constituency is $x$, while that of B's constituency is $1-x$. It is reassuring to find that, ceteris paribus, $x$ responds to changes in the choice variables in an intuitively appealing manner: ${ }^{10}$

(i) $\quad x$ increases with $M$, i.e. higher military expenditure by A can secure him a bigger constituency;

(ii) $\quad x$ decreases with $m$, i.e. higher military expenditure by B decreases the size of the A's constituency;

(iii) $\quad x$ increases with $\lambda_{A}$, i.e. as player A locates the public good further from the capital, the size of his constituency increases;

(iv) $\quad x$ increases with $\lambda_{B}$, i.e. as player B locates the public good closer to the boundary "1", the size of her constituency decreases.

We assume that the competitors move simultaneously, and we look for the Nash equilibrium of this game. The basic trade-off for both players is clear from (1) and (2): by spending more on military equipment and/or by locating the public good closer to the center, each of them can increase the size of his or her constituency (i.e. the tax base), but only at the cost of decreased private profits from governing. There will be an optimal mix of military expenditure and public good location that allows each player to maximize his rents for given actions of the other player.

\footnotetext{
${ }^{9}$ In this setting, an increase in $M$ (in $m$ ) would shift the rightmost (leftmost) curve down.
} 
The analytical derivation of the equilibrium can be found in the appendix. ${ }^{11}$ The optimal mix of $\lambda_{A}, \lambda_{B}, M, m$ depends on the exact functional forms, i.e., we may have interior or corner solutions for some or all of the variables, depending on parameter values. For presentation purposes, in this section we concentrate on three informative equilibria. In the first, players spend no money on military equipment and they locate their public goods as close to the center as possible; in the second they rely solely upon military expenditure; in the third, they deploy both instruments in their competition for power. These are only some of the possible configurations that the equilibrium can take, depending on functional forms; however, they can be useful to highlight the peculiar effects of each instrument of political competition.

\section{EQUILIBRIUM - TYPE 1: NO MILITARY EXPENDITURE}

If the following inequalities hold: ${ }^{12}$

$$
\frac{t G^{\prime}(0)}{V^{\prime}\left(x-\lambda_{A}{ }^{*}\right)+V^{\prime}\left(\lambda_{B}{ }^{*}-x\right)}<H^{\prime}(0), \frac{t^{\prime}(0)}{V^{\prime}\left(x-\lambda_{A}{ }^{*}\right)+V^{\prime}\left(\lambda_{B}{ }^{*}-x\right)}<h^{\prime}(0)
$$

then the equilibrium is described by the following conditions:

$$
\begin{aligned}
& M^{*}=0 \\
& m^{*}=0
\end{aligned}
$$

$$
\frac{t V^{\prime}\left(x-\lambda_{A}^{*}\right)}{V^{\prime}\left(x-\lambda_{A}^{*}\right)+V^{\prime}\left(\lambda_{B}^{*}-x\right)}=C^{\prime}\left(\lambda_{A}^{*}\right)
$$

$$
-\frac{t V^{\prime}\left(\lambda_{B}^{*}-x\right)}{V^{\prime}\left(x-\lambda_{A}^{*}\right)+V^{\prime}\left(\lambda_{B}^{*}-x\right)}=c^{\prime}\left(\lambda_{B}^{*}\right)
$$

$$
\alpha_{A}-\alpha_{B}=V\left(x-\lambda_{A}^{*}\right)-V\left(\lambda_{B}^{*}-x\right)
$$

\footnotetext{
${ }^{10}$ See the appendix for the analytical expressions of the derivatives.

${ }^{11}$ Here it is enough to mention that, being this a concave programming problem, the critical points of the competitors' objective functions are global maxima.

${ }^{12}$ Equilibrium type 1 occurs if (6) holds and, implicitly, (12) does not.
} 
In interpreting this equilibrium, it is useful to note that the left hand side of the inequalities in (6) suggest the extent to which $x$ will increase, hence tax revenue will grow, with increases in military spending. For military spending to remain at 0 , then the incremental benefit to the competitors from increasing the size of their tax-paying constituency must be less than marginal costs of increasing the size of the military. A and B then restrict their competition to "policy space," i.e. to the location of public goods. Note that the eft hand side of equations 9 and 10 are, respectively, $t \partial x / \partial \lambda_{A}{ }^{*}$ and $t \partial(1-x) / \partial \lambda_{B}{ }^{*}$. The competitors therefore choose the location of the public good so that the marginal revenue from an increase in equals its marginal cost.

The following results hold: $:^{13}$

Result 1: $\left|x-\lambda_{A}{ }^{*}\right|>\left|x-\lambda_{B}^{*}\right|$

Proof: follows from the left-hand side of (11) being positive and $V^{\prime}(\cdot)>0$.

Result 2: If $c(\lambda)=C(1-\lambda)$, then $\lambda_{A}{ }^{*}>1-\lambda_{B}{ }^{*}$.

Proof: see the appendix.

Result 1 confirms that candidate attributes count, and in interesting ways. A offers lower-quality services to his constituency in the sense that $x$, which defines the periphery of A's coalition, lies further from $\lambda_{A}{ }^{*}$ than does the periphery of B's constituency from $\lambda_{B}{ }^{*} \cdot{ }^{14}$ An important lesson is therefore clear: a competitor that is popular because of his identity can provide inferior services to his people, in the sense that the average distance of his clients from the public good is greater than that of his competitor's clients from the good provided by the latter. ${ }^{15}$

\footnotetext{
${ }^{13}$ Note that the results hold under the conditions stated for the relevant type of equilibrium, e.g., results 1 and 2 hold under condition (6), result 3 will hold under condition (12), etc.

${ }^{14}$ A's constituency nonetheless remains better off supporting A than B because of A's "valence advantage".

${ }^{15}$ Result 1 says that A's public good lies further from the ideal point of the marginal citizen than does B's. However, this easily translates into A's public good being further from the ideal point of the average citizen in
} 
Result 2 suggests that when neither player possesses an intrinsic cost advantage in the provision of public goods, the competitor with the higher valence will locate public goods further from the end point ${ }^{16}$. He can therefore gain a bigger following, and secure greater revenues, than can his competitor.

Note the irony: Because of the "political bounce" that A secures from his inherent appeal (i.e. from the fact that $\alpha_{A}>\alpha_{B}$ ), he is able to capture political support from constituents further to the right, and so secure a larger constituency than the rival. And yet, for the same reason, A can provide a public good of lesser value to the average citizen in his constituency.

\section{EQUILIBRIUM - TYPE 2: MIIITARY EXPENDITURE ONLY}

If the following inequalities hold: ${ }^{17}$

$$
\frac{t V^{\prime}(x)}{V^{\prime}(x)+V^{\prime}(1-x)}<C^{\prime}(0), \quad \frac{t V^{\prime}(1-x)}{V^{\prime}(x)+V^{\prime}(1-x)}<-c^{\prime}(1)
$$

then the equilibrium is described by the following conditions:

$$
\begin{aligned}
& \lambda_{A}{ }^{*}=0 \\
& \lambda_{B}{ }^{*}=1 \\
& \frac{t G^{\prime}\left(M^{*}\right)}{V^{\prime}(x)+V^{\prime}(1-x)}=H^{\prime}\left(M^{*}\right) \\
& \frac{t g^{\prime}\left(m^{*}\right)}{V^{\prime}(x)+V^{\prime}(1-x)}=h^{\prime}\left(m^{*}\right) \\
& \alpha_{A}-\alpha_{B}=V(x)-V(1-x)+g\left(m^{*}\right)-G\left(M^{*}\right)
\end{aligned}
$$

A's constituency. In fact, we can rule out $\lambda_{A}{ }^{*}<\lambda_{B}{ }^{*}<x$, because in this case B would be better off by increasing $\lambda_{B}{ }^{*}$. Once we know that $\lambda_{A}{ }^{*}<x<\lambda_{B}{ }^{*}$, the average distance of A's supporters from the public good is $x / 2$. We thank one referee for pointing this out to us.

16 In stating result 2, we are interested in examining the competitors' policies under conditions of symmetry in costs. If player A faced higher costs than B, this might prevent him from locating the public good far from 0 ; result 2 would then no longer necessarily apply.

${ }^{17}$ Equilibrium type 2 occurs if (12) holds and, implicitly, (6) does not. 
Note that the left hand sides of (15) and (16) are, respectively, $t \partial x / \partial M^{*}$ and $t \partial(1-x) / \partial m^{*}$. Conditions (15) and (16) therefore say that both players purchase military equipment up to the point where the benefit from the last unit (i.e. the increase in tax revenues coming from the increased $x$ ) equals its cost. Dividing condition (15) by (16), we see that the relative amount of military coercion purchased by A and B depends on their relative cost structure and on the relative effectiveness of their military.

$$
\frac{G^{\prime}\left(M^{*}\right)}{g^{\prime}\left(m^{*}\right)}=\frac{H^{\prime}\left(M^{*}\right)}{h^{\prime}\left(m^{*}\right)}
$$

The following result can be established for the case of identical cost functions.

Result 3 (a) When $H(\cdot) \equiv h(\cdot)$ and $G(\cdot) \equiv g(\cdot)$, then $M^{*}=m^{*}$. (b) When $H(\cdot) \equiv h(\cdot)$ and $G^{\prime}(M)>[<] g^{\prime}(m)$ for all $M=m$, then $M^{*}>[<] m^{*}$. (c) When $G(\cdot) \equiv g(\cdot)$ and $H^{\prime}(M)<[>] h^{\prime}(m)$ for all $M=m$, then $M^{*}>[<] m^{*}$.

Proof: see the appendix.

Parts (b) and (c) of Result 3 simply state that, ceteris paribus, the player with the greater marginal returns and/or the lower marginal costs of military force will spend more in his military capabilities.

Result 3(a) is more interesting and addresses the case in which neither enjoys a cost advantage. According to result 3(a), when changes in $M$ and $m$ produce the same increment in $G(\cdot)$ and $g(\cdot)$, respectively, then both competitors will choose the same level of military investment. Note that A's greater valence index does not influence either player's decision regarding military expenditure (this will no longer be true when we treat military force and public goods as complements in section 6). Note also that when both competitors spend the same amount on 
military equipment, the size of their constituencies remains the same as if they both spent nothing (in terms of figure 1 , both curves shift up by the same vertical distance and the intersection $x$ remains unaltered.). The outcome is thus Pareto inefficient and the competitors could save by jointly abolishing $M$ and $m$ while maintaining the same revenue. Neither possesses an incentive to disarm unilaterally, of course. In the absence of external coordination and enforcement, socially harmful military expenditure therefore remains privately advantageous and the best response to the anticipated actions of the other.

\section{EQUILIBRIUM - TYPE 3: POSITIVE MIX OF PUBLIC GOOD AND MILITARY EXPENDITURE}

Finally, the "interior" equilibrium, in which each competitor uses a mixture of both instruments, is captured by the following conditions:

$$
\frac{t V^{\prime}\left(x-\lambda_{A}{ }^{*}\right)}{V^{\prime}\left(x-\lambda_{A}{ }^{*}\right)+V^{\prime}\left(\lambda_{B}{ }^{*}-x\right)}=C^{\prime}\left(\lambda_{A}{ }^{*}\right)
$$

$$
\frac{t V^{\prime}\left(\lambda_{B}{ }^{*}-x\right)}{V^{\prime}\left(x-\lambda_{A}{ }^{*}\right)+V^{\prime}\left(\lambda_{B}{ }^{*}-x\right)}=-c^{\prime}\left(\lambda_{B}{ }^{*}\right)
$$

$$
\frac{t G^{\prime}\left(M^{*}\right)}{V^{\prime}\left(x-\lambda_{A}^{*}\right)+V^{\prime}\left(\lambda_{B}^{*}-x\right)}=H^{\prime}\left(M^{*}\right)
$$

$$
\frac{\operatorname{tg}^{\prime}\left(m^{*}\right)}{V^{\prime}\left(x-\lambda_{A}{ }^{*}\right)+V^{\prime}\left(\lambda_{B}{ }^{*}-x\right)}=h^{\prime}\left(m^{*}\right)
$$

$$
\alpha_{A}-\alpha_{B}=V\left(x-\lambda_{A}^{*}\right)-V\left(\lambda_{B}^{*}-x\right)+g\left(m^{*}\right)-G\left(M^{*}\right)
$$

The following results can be established.

Result 4: If $C^{\prime}\left(\lambda_{A}\right)<\left|c^{\prime}\left(\lambda_{B}\right)\right|, \forall \lambda_{A}, \lambda_{B}$, and $G(\cdot) \equiv g(\cdot)$, then $\left|x-\lambda_{A}{ }^{*}\right|<\left|x-\lambda_{B}{ }^{*}\right|$ and $M^{*}<m^{*}$.

Result 5: If $H^{\prime}(M)<h^{\prime}(m), \forall M=m$, and $G(\cdot) \equiv g(\cdot)$, then $\left|x-\lambda_{A}{ }^{*}\right|>\left|x-\lambda_{B}{ }^{*}\right|$ and $M^{*}>m^{*}$. 
Result 6: In general, $M^{*}=m^{*}>0$ is a possible outcome.

Proof: see the appendix.

Result 4 refers to a situation where A enjoys lower marginal costs in the provision of public goods at any location. In seeking popular support, A would then rely principally on the provision of public goods and spend less on its military than would B, its rival. A would therefore locate the public good closer to its marginal supporter than would B. Note the contrast with Result 1. In this equilibrium, when its opponents possess a competitive advantage in the procurement of military resources, conflict serves as a disciplining device for the competitor with the higher "valence" and forces it to reach out to the periphery in providing the public good.

Result 5 refers to a case where A enjoys lower marginal costs of military action. A economizes on the provision of the public good by locating it relatively close to 0 and by using military expenditure to secure his constituency. In this case, military force reinforces the effect captured in Result 1: A's advantage in military procurement encourages it to economize on the costs of public good provision, and hence to increase the distance of the public good from the periphery of its constituency.

Result 6 highlights the Pareto inefficiency of the equilibrium. Both players would be better off were they to coordinate and set $M=m=0$. But neither has an incentive to move unilaterally. And hence demilitarization does not occur.

In Sections 5-7, we explore alternative specifications of our model. In Sections 5 and 6, we focus on the use of force. Section 5 examines expressions that capture intuitively appealing alternative understandings of the impact of military force and confirm that our results are robust to different specifications. Section 6 focuses on the interaction between expenditures on military force and local public goods. In it we again find that our results are robust, save in one important instance which we report as Result 7.

\section{The technology of conflict}


In this section, we propose alternative specifications of the technology of conflict. A glance at equations (3) and (4) highlights the importance of doing so, for they treat the impact of one politicians use of force as independent of the force levels of the opponent. While simplifying the analysis, this specification is less appealing that alternatives suggested by Hirshleifer (1989), in which the impact of military expenditures depends upon the difference or the ratio of the competitors' resource commitments. Nor does our expression capture the citizen's possible sense of loss over higher levels of military spending resulting, perhaps, from the possibly increased chance of conflict. In this section, we therefore check the robustness of our conclusions to these alternative conceptions of the impact of military expenditure, and find that it offers the gain of tractability while yielding conclusions consistent with those derived from more plausible - but slightly more complex - specifications.

The first alternative we consider is one in which the loss in utility of the citizens depends on the difference between the military spending of the opponent and that of the competitor that they support. Expressions (3) and (4) are thus replaced by:

$$
\begin{aligned}
& U(l, A) \equiv \alpha_{A}-V\left(\left|l-\lambda_{A}\right|\right)-g(m-M) \\
& U(l, B) \equiv \alpha_{B}-V\left(\left|l-\lambda_{B}\right|\right)-G(M-m)
\end{aligned}
$$

where $G(\cdot)$ and $g(\cdot)$ satisfy assumption A5. The marginal citizen in lemma 1 is now defined implicitly by the condition $\alpha_{A}-V\left(x-\lambda_{A}\right)-g(m-M)=\alpha_{B}-V\left(\lambda_{B}-x\right)-G(M-m)$.

The only difference with the previous analysis lies in the form of the derivatives of $x$ with respect to $M$ and $m$ : in particular we have that, for any $G(\cdot)$ and $g(\cdot)$

$$
\frac{\partial x}{\partial M}=\frac{G^{\prime}(M-m)+g^{\prime}(m-M)}{V^{\prime}\left(x-\lambda_{A}\right)+V^{\prime}\left(\lambda_{B}-x\right)}=-\frac{\partial x}{\partial m} .
$$

Substituting the new derivatives in the first order conditions (15) and (16) for equilibrium type 2 --or in (21) and (22) for equilibrium type 3-- yields $H^{\prime}\left(M^{*}\right)=h^{\prime}\left(m^{*}\right)$. Parts (a) and (c) of 
Result 3 are thus strengthened; they hold even when the functions $G(\cdot)$ and $g(\cdot)$ are not identical. Part (b) no longer applies.

To grasp the intuition behind this, consider what happens in figure 1 when the competitors change their military spending, and in particular suppose that player B increases $m$, other things being equal. While in our baseline specification such increase produced a downward shift of the leftmost curve, now it produces a downward shift of the leftmost curve and an upward shift of the righmost curve: both shifts lead to a lower $x$. Furthermore, in our baseline specification a decrease in $M$ of the same magnitude as the decrease in $m$ would have had the same qualitative impact (shifting up the rightmost curve and lowering $\mathrm{x}$ ), but not necessarily the same quantitative impact, due to the possibility that $G^{\prime}\left(M^{*}\right) \neq g^{\prime}\left(m^{*}\right)$. In the new specification, instead, the special way in which $M$ and $m$ enter $G(\cdot)$ and $g(\cdot)$ renders everything symmetric, in that an increase in $m$ or a decrease in $M$ of the same amount will shift either curve in exactly the same way. Intuitively, this happens because by construction what matters is only the difference between military capabilities, and not the levels.

The second variant of the technology of conflict that we explore is one in which the loss in utility depends on the share of military spending of each competitor, so that expressions (3) and (4) are replaced by:

$$
\begin{aligned}
& U(l, A) \equiv \alpha_{A}-V\left(\left|l-\lambda_{A}\right|\right)-g\left(\frac{m}{M+m}\right) \\
& U(l, B) \equiv \alpha_{B}-V\left(\left|l-\lambda_{B}\right|\right)-G\left(\frac{M}{M+m}\right)
\end{aligned}
$$

where $G(\cdot)$ and $g(\cdot)$ satisfy assumption A5 for $M+m>0$, and $G(\cdot)=g(\cdot)=0$ for $M+m=0$. The marginal citizen in lemma 1 is now defined implicitly by the condition $\boldsymbol{\alpha}_{A}-V\left(x-\lambda_{A}\right)-g[m /(M+m)]=\boldsymbol{\alpha}_{B}-V\left(\lambda_{B}-x\right)-G[M /(M+m)]$.

Again, the difference with the previous analysis lies in the form of the derivatives of $x$ with respect to $M$ and $m$ : 


$$
\begin{aligned}
& \frac{\partial x}{\partial M}=\frac{m}{(M+m)^{2}} \cdot \frac{G^{\prime}[M /(M+m)]+g^{\prime}[m /(M+m)]}{V^{\prime}\left(x-\lambda_{A}\right)+V^{\prime}\left(\lambda_{B}-x\right)} \\
& \frac{\partial x}{\partial m}=-\frac{M}{(M+m)^{2}} \cdot \frac{G^{\prime}[M /(M+m)]+g^{\prime}[m /(M+m)]}{V^{\prime}\left(x-\lambda_{A}\right)+V^{\prime}\left(\lambda_{B}-x\right)} .
\end{aligned}
$$

The impact of military spending on the size of the competitors' constituencies is not symmetric, as was the case in the "difference" formulation. In particular, ceteris paribus, the gain in political following for given increase in military is now higher, the greater the share of total military force contributed by the opponent. ${ }^{18}$

Substituting the new derivatives in the first order conditions we find that our results still apply . In particular, the left hand side of equation (18) simplifies to $m^{*} / M^{*}$ so that again parts (a) and (c) of Result 3 hold more generally regardless of the functional form of $G(\cdot)$ and $g(\cdot){ }^{19}$

Finally, we can extend our formulation by incorporating the loss from increased aggregate military spending - say, due to higher probability of conflict—into the citizens' utility. ${ }^{20} \mathrm{We}$ could capture this loss by adding the term $-L(M+m)$, with $L^{\prime}(\cdot)>0$, in expressions (3) and (4), or in the successive formulations (3')-(4') and (3') $-\left(4^{\prime \prime}\right)$. While the addition of such a term would provide an intuitive representation of the welfare effects of military spending, it would not affect the analysis; the new terms cancel in the condition that defines the marginal citizen, namely equation (5).

\section{Complementarity between military expenditure and public goods}

Thus far, we have treated expenditure on public goods and military forces as substitutes. It is possible, however, that they might be complements, in that increased security may enhance the utility derived from a given quantity of public services. In our model, the satisfaction generated by the public good declines with distance. In such a context, increased military protection could reduce the costs of access to public services, raising the benefits to people in every location.

\footnotetext{
${ }^{18}$ This is a consequence of our assumption of decreasing returns in A5.

${ }^{19}$ Clearly, part (b) of result 3 no longer applies.

${ }^{20} \mathrm{We}$ thank one referee for suggesting this.
} 
To capture this possibility, we represent military expenditures as entering individual utilities through the functions $F(M)>0$ and $f(m)>0$, respectively, that multiply $V(\cdot)$. Individual utilities from supporting A and B therefore become:

$$
\begin{aligned}
& U(l, A) \equiv \alpha_{A}-F(M) V\left(\left|l-\lambda_{A}\right|\right) \\
& U(l, B) \equiv \alpha_{B}-f(m) V\left(\left|l-\lambda_{B}\right|\right)
\end{aligned}
$$

Regarding the functions $F(\cdot)$ and $f(\cdot)$, we assume:

$$
\begin{aligned}
& F^{\prime}(\cdot)<0, F^{\prime \prime}(\cdot)>0, F(0)=1 \\
& f^{\prime}(\cdot)<0, f^{\prime \prime}(\cdot)>0, f(0)=1
\end{aligned}
$$

Assumption (A7) states that the higher $M$ the lower $F(M)$ and the lower the "effective disutility" $F(M) V(\cdot){ }^{21}$ that military expenditures yield decreasing returns; and that when a competitor makes no military expenditure, then individuals' disutility remains unchanged.

Interestingly, this modification fails to alter the qualitative nature of our results, save in one instance. The findings in Section 3 remain generally robust to this change in specification. The exception is best illustrated by re-analyzing the second equilibrium, wherein competitors devote resources solely to the purchase of military equipment. When military expenditures constituted substitutes for public goods, then, by Result 3, competitors endowed with the same technologies purchased the same amount of arms. When military expenditures constitute complements to public goods, however, then:

Result 7: When $H(\cdot) \equiv h(\cdot)$ and $F(\cdot) \equiv f(\cdot)$, then $M^{*}>m^{*}$ and $x>1 / 2$.

Proof: see the appendix.

Result 7 suggests that when both competitors have access to the same technology $(F, f)$ and cost functions $(H, h)$, the competitor with an intrinsic advantage will then be able to secure a larger increase in the size of her constituency for any increase in military spending. Under this specification,

\footnotetext{
${ }^{21}$ Similarly for $m$ and $f(m)$.
} 
then, A will spend more than B on military equipment, gain a larger constituency (indeed, the support of the majority of the population), and thereby secure superior access to public revenues.

When military expenditures constitute complements rather than substitutes for public goods, they then amplify the political advantages of the competitor who possesses a favorable personal identification and encourage her to outspend the rival in military power.

[Insert figure 2]

To comprehend the reasons for this result, consult figure 2. When military expenditure enters multiplicatively, it makes the two inverted-U curves "flatter" while leaving the height of the maximum points $\left(\alpha_{A}\right.$ and $\left.\alpha_{B}\right)$ unaltered. While the citizens located at $\lambda_{A}$ and $\lambda_{B}$ experience no disutility from public good location, the utility of the others decreases less the greater the military force of the competitor. Starting from $M=m=0$, suppose now that A and B unilaterally increase their military forces by the same amount $k$. Then the vertical shift of $U\left(l, \lambda_{A}=0\right)$ and $U\left(l, \lambda_{B}=1\right)$ will be the same for symmetric distances from the endpoints but, due to the concavity of $U(\cdot)$ coupled with $\alpha_{A}>\alpha_{B}$, the (horizontal) gain will be greater for the constituency of A, who moves to the right, than for B, who moves to the left. ${ }^{22}$

This counterintuitive result, thus, shows that when military expenditure and public good provision are complements rather than substitutes, having a higher "intrinsic popularity" does not translate into saving money on military expenditure, as one might think. On the contrary, it gives the more popular competitor an incentive to spend more. ${ }^{23}$

\section{Reformulating the valence factor}

Until now we have treated $\alpha_{A}$ and $\alpha_{B}$ as valence factors: attributes of the political competitors that affect the citizens' valuations of the competitors uniformly, regardless of the politician's choice of public goods or military expenditures. Such factors could include the citizens' perceptions of her

\footnotetext{
${ }^{22}$ See the appendix for a more precise explanation.

${ }^{23}$ The counterpart to result 7 is that the only way to have B using more military force than A is that at least one of two things happen: (i) B has lower marginal costs for any level of military expenditure (e.g., has access to cheaper military equipment); (ii) military coercion has a bigger impact on individuals' utilities if exercised by B than if exercised by A (e.g., they perceive B as much more threatening).
} 
integrity, skill, or "charisma." Such attributes, we have found, affect the equilibrium outcome. When neither political leader employs force, then the leader with the higher valence is able to capture the larger constituency and at less average cost (Result 1). And when the competitors deploy both force and public goods, then the advantage of the more popular candidate is increased when she has lower marginal costs of military preparedness (Result 5) but reduced when she has lower marginal costs for supplying public goods (Result 4).

Of perhaps greater interest, however, is the impact of attributes that are valued differently by citizens located at different positions. Recasting the $\alpha^{\prime} s$ such that their value is a function of location (l) enables us to explore the impact of evaluations that arise from religious, ethnic, or cultural differences, which often vary by geographic location. Seeking to move beyond an understanding of the impact of personal attributes to an understanding of the impact of cultural preferences, we therefore respecify $\alpha$. In the new formulation, the utility of a citizen located at $l$ from supporting competitor A or B is given, respectively, by:

$$
\begin{array}{lr}
U(l, A) \equiv \alpha_{A}(l)-V\left(\left|l-\lambda_{A}\right|\right)-g(m) & \alpha_{A}^{\prime}(l)<0 \\
U(l, B) \equiv \alpha_{B}(l)-V\left(\left|l-\lambda_{B}\right|\right)-G(M) & \alpha_{B}^{\prime}(l)>0
\end{array}
$$

where the sign on the first derivatives of $\alpha_{A}$ and $\alpha_{B}$ with respect to $l$ indicates that the "intrinsic preference" for competitor $\mathrm{A}$ is higher the closer a citizen is to 0 , and vice versa the preference for $\mathrm{B}$ is higher the closer a citizen is to $1 .^{24}$

Notice that we are not saying that a citizen prefers either competitor because he or she will locate the public good close to him: this element of geographical preference is already included in our utility functions through the term $V(\cdot)$. The geographical preference we are concerned with in this

\footnotetext{
${ }^{24}$ If the relationship between the citizens' location and their intrinsic preference for A versus B were not monotonic, our basic conclusions would still hold in terms of aggregate mass of supporters, but the characterization of the marginal citizen $x$ such that everyone to the left prefers A and everyone to the right prefers B would no longer apply.
} 
section is independent of the competitors' policy choices, and may be interpreted as higher trust for someone originally "close to you". 25

The equation identifying the "marginal supporter" $x$ now becomes:

$$
\alpha_{A}(x)-V\left(x-\lambda_{A}\right)-g(m)=\alpha_{B}(x)-V\left(\lambda_{B}-x\right)-G(M) .
$$

To understand the implications of this new formulation, consider the case in which neither competitor possesses an intrinsic advantage, i.e. where $\alpha_{A}(l)=\alpha_{B}(l), \forall l$. Under this assumption, equation (28) becomes:

$$
V\left(x-\lambda_{A}\right)+g(m)=V\left(\lambda_{B}-x\right)+G(M) .
$$

Denote by $x$ the solution to (29), and refer to this value as the "unbiased" marginal citizen. Suppose without loss of generality that $\alpha_{A}(x)>\alpha_{B}(x)$; then, ceteris paribus, the value of $x$ that solves (28) must be greater than $x .{ }^{26}$ In other words competitor A, who enjoys an "cultural advantage" for the unbiased citizen $x$, manages to push the boundaries of his constituency beyond $x$, thus gaining revenue compared to the case where citizens only care about military security and local public goods. Loyalty in our model gives political leverage to the competitor who has relatively more of it.

\section{[Insert figures $3 \mathrm{a}$ and $3 \mathrm{~b}$ ]}

To comprehend the argument, suppose that $M=m$ and consider figures $3 \mathrm{a}$ and $3 \mathrm{~b}$. The top panel depicts a situation where neither player has an intrinsic cultrural advantage, and the intersection between the two curves is $x$ as defined by (29). In the bottom panel we introduce an ethnic bias and locate the new intersection $x$ as defined by (28). In figure $3 b$, the functions $\alpha_{A}(l)$ and $\alpha_{B}(l)$

\footnotetext{
${ }^{25}$ Being interested in the trade off between the first two channels, we ignore "manipulation" of personal attributes, as through media campaigns.

${ }^{26}$ When evaluated at $x$, the left-hand side of (28) is greater than the right-hand side. In order to balance the two sides, $x$ has to increase, because $V^{\prime}(\cdot)>0, \alpha_{A}^{\prime}(\cdot)<0$ and $\alpha_{B}^{\prime}(\cdot)>0$.
} 
modify the shape of the two curves so that, by comparison with those in figure 3a, they are relatively flatter towards the endpoints and steeper towards the center of the distribution.

Consider two citizens located at the same distance from $\lambda_{A}$, one to its left and one to its right, and the utility they derive from supporting A. Given our assumption that $\alpha_{A}^{\prime}(l)<0$, the utility of the citizen to the left is higher than that of the citizen to the right, despite the identical disutility resulting from their distance from the public good. Cultural identication thus introduces an asymmetry in the shape of the curves in figure $3 b^{27}$ If we assume $\alpha_{A}(x)>\alpha_{B}(x)$, then the intersection between the two curves will occur to the right of $x$.

While the specification better captures the nature of regional or ethnic loyalty, analysis of the model yields results that bear no important difference from those of the original model. The only meaningful difference arises from the entry of $\alpha_{B}^{\prime}(x)-\alpha_{A}^{\prime}(x)>0$ into the denominator on the left hand side of equations (19)-(22). As a result, equilibrium implies that, ceteris paribus, $M^{*}, m^{*}$, $\lambda_{A}{ }^{*}$ are closer to 0 , and $\lambda_{B}{ }^{*}$ lies closer to 1 . Intuitively, by exploiting the political loyalty of their constituencies, the competitors can garner even greater rents by spending less on military equipment and public good provision.

\footnotetext{
${ }^{27}$ Whether the two curves are the mirror image of each other or not depends on the exact shape of $\alpha_{A}(l)$ and $\alpha_{B}(l)$.
} 


\section{Political implications}

In this paper, we have explored the properties of a model in which rent-seeking élites compete for followers. The motivation for the model derives from observing the politics of the developing areas. There, states are weak and lack a monopoly over the use of force. Political competition is not constrained by democratic institutions. And political competition is organized by prominent individuals, to whom citizens are drawn by ties of personal loyalty, the distribution of pork, and fear.

Among the most interesting of our results are those that apply to violence. Clearly, some political groups possess a military advantage over others. Those based on pastoralism, for example, can readily mobilize young warriors who have refined their military skills in the course of protecting their livestock - and stealing the cattle of others. Those engaged in arable production incur higher costs in recruiting armed forces; fighting is rivalrous, rather than complementary, to arable production. Examples of such differences would include the contrast between the Nandi and Kikuyu in Kenya or the Ndebele and Shona in Rhodesia (now Zimbabwe), respectively; or between pastoralists and agriculturalists in contemporary Chad or Uganda. As Result 5 would suggest, that, as might be expected, when such groups possess a relative advantage in warfare, their leaders will find it advantageous to concentrate resources upon coercive action. Furthermore - again as Result 5 would suggest - they would allocate resources in a Spartan manner, with a relatively large portion of the resources going to military activity, relatively few being devoted to broaden access to public goods, and the rank and file nonetheless continuing to offer support.

Also interesting are the implications for the impact of cultural identities on politics. Recall from Section 8 that when the valence factor that enters a citizen's preference for a candidate is allowed to vary by location, then the results of the original model "go through," and, in critical respects, are strengthened. Interpreting this factor as an expression of political identity, we then gain insight into the impact of culture upon politics in weak states. Result 7 suggests that, for a political organizer, cultural identification provides political capital. When military force and local public goods constitute complements, then possessing a stronger claim to the loyalties of citizen taxpayers enables 
a competitor to secure a larger increase in the membership of his movement for any increase in military capacity, even when the opponent possesses the same military technology and cost function.

In pondering this result, it is useful to think of militant organizations, such as Hamass. Many such groups supply local public goods - settlements, schools, and clinics - and recruit a military. They also derive a major portion of their strength not only from the provision of local benefits and military security, but also from their appeal to deep-seated religious identifications. By Result 7 they therefore find it advantageous to spend more on military equipment, and thereby gain an increase in the size of their tax base and political constituency. The cultural loyalties that such groups command thus enhance the productivity of the military resources they bring to bear when competing for political support.

Interpreting valence attributes as deriving from cultural preferences also provides insight into the discrepancy between the public regard in which many political leaders are held than the private advantages that they extract from politics. Results 1 and 2 confirm that leaders that elicit high levels of individual loyalty can provide public goods of lower average value to the citizens in their constituency. And when political competitors find it advantageous to deploy both public works and military force, then when political loyalties derive from geographically varying political preferences, then $M^{*}, m^{*}, \lambda_{A}{ }^{*}$ are closer to 0 , and $\lambda_{B}{ }^{*}$ lies closer to 1 in the resultant equilibrium. These results suggest that political leaders of cultural movements can spend less in providing public goods and military security and so can derive greater rents from politics.

The results of our analysis thus offer important insights into politics in weak states. They also offer insight into possible sources of order. Results 3 and 6 underscore the incentives for political reconciliation. While spending resources on military equipment, the competitors, they emphasize, may achieve no gain, in terms of an expansion in the size of their constituencies. Competing élites would therefore find it advantageous to de-militarize, should the reductions be coordinated. Under such circumstances, external interventions might be welcomed. Not only do our findings suggest a positive role for external agencies; they also offers guidance for how they should target their interventions. Result 4 suggests, for example, that those seeking arms reductions might target the costs of public good procurement by the elite that enjoys the more intense political loyalty. 
By lowering the costs of providing public services, it can strengthen incentives for élites to expand their constituency by devoting resources to the repositioning of public goods to the political margins and to reduce their expenditures upon their military. It also provides assurances for those who might fear that external support for "peaceful" expenditures by such an elite might only free up resources that it would then devote to military spending; under the conditions assumed, while the resources may be fungible, they would not be devoted to military expenditures. Rather, the élites would employ them to provide public goods, and even tolerate superior military spending on the part of political rivals.

While under the premises stipulated in Result 4, assistance might promote peaceful reform, Result 5 offers an important warning: it points to conditions under which those who offer military assistance might lower the welfare of those whose interests they seek to promote. If the leader who evokes the stronger loyalty also possesses a cost advantage in the use of military force, then the increase in resources would result in efforts at military expansion, even while "starving" the marginal member of the group of public goods. The paper thus offers words of encouragement and points of caution to those who might seek to promote the transition from military conflict to peaceful political competition in the developing world.

\section{Conclusions}

This article has explored political competition in weak states. Modification of the assumptions of the classical spatial model has enabled us to explore themes often ignored in the study of political competition in stable democracies. It has enabled us to gain insight into the ways in which those with aspirations for wealth and power in weak states can organize political followings and into the implications for political order. 
In exploring the implications of our analysis, we might best begin by returning to Results 1 and 2 in Section 4, which characterize the outcome of peaceful political competition, i.e. competition in which politicians abjure the use of force. Results 1 and 2 suggest that the mobilization of political identities pays, in two distinct senses:

1. The competitor who commands the greater loyalty gains a political advantage. Rather than being captured by her constituency, she gains room to maneuver. Even though subject to the same cost function as her competitor, without fear of losing political support, she can locate the public good further toward the center (Result 2).

2. The competitor who commands the greater political loyalty will be able to attract citizens whose ideal points lie at greater distance from the location of the public good. Even while providing relatively "lower quality" services to the marginal citizen, this competitor will be able to retain her political support. She thereby gains a revenue advantage (Result 1 ).

Those who can mobilize political identities thus gain both political and economic advantages. They are better positioned to build broad political constituencies and to extract private rents from politics.

Among the numerous examples that could be cited, one best serves to underscore the political advantages conferred upon those endowed with "positive valence": the oft-told failure of class-based organizations to form in constituencies in which ethnic loyalties remain strong. This pattern most often noted by scholars who address the weakness of working class movements. Students of Africa note the power of ethnic loyalties to fragment class-based organizations (Epstein 1958, Melson and Wolpe 1970). Perry (1998) documents the frustration of political organizers in China, who were compelled to suppress regionally-based organizations in Shanghai, in order to build a disciplined socialist movement. And numerous students of American politics (e.g. Lipset 1959, Eries 1988) note that attempts to develop a socialist party in the United States fell afoul the ethnicbased organization of working-class immigrants. In each instance, political élites are often able to 
survive as leaders of low-income groups, even while refraining from championing the collective interests of workers.

Our analysis suggests a reason for this regularity: given the positive valence that ethnic leaders receive from their cultural identities, working class élites could refrain from costly efforts at organizing. They could attract a following even while economizing on efforts to build class-based organizations or to engage in collective action, such as general strikes. Result 1 suggests why working class leaders would chose to behave in this manner; Result 2 suggests why they might be able to get away with dong so. Even though competitors might bid for the pivotal supporter - i.e. locate $\lambda_{B}$ closer to $\mathrm{x}$ than is $\lambda_{\mathrm{A}}-$ the marginal supporter nonetheless would remain loyal to $\mathrm{A}$. The loss resulting from inferior policies is compensated by the gains from ethnic identification.

The model thus offers insight into the oft-noted conflict between cultural and economic interests in the politics of the working class and the capacity of cultural identities to disrupt classbased movements. It also captures the mixture of opportunism, corruption, and political popularity that often characterizes the leadership of populist movements (see Erie 1988).

The model also offers insight into the use of force. In weak states, political organizers not only take policy stands; they also recruit military organizations. To comprehend the behavior of such élites, we turn to Result 7. There we learn of the impact of ethnic loyalty upon the use of military capabilities. Where force is employed to enhance the capacity of citizens to benefit from public goods, then, by Result 7, the competitor who elicits the greater loyalty can employ force more productively. As a consequence, they devote more resources to its use and employ it to expand their political boundaries. Examples from the Middle East, Afghanistan, Somalia, and other settings appear to conform to the patterns derived in this finding. In such settings, on the one hand, ethnic political movements appear to their members as benevolent providers of public gods: clinics, welfare centers, mosques, and temples, for example. Their military stand guard, protecting those who would make use of these facilities. But to their rivals, such communities appear as political aggressors. Their leaders appear to devote a large portion of their resources to the use of force and to pursue policies that secure the outward expansion of their political frontiers. Result 7 suggests the foundations for - and the validity of - these divergent perceptions. When governments employ force so as to enhance the capacity to derive utility from the consumption of the facilities they provide, 
then, all else being equal, the government that enjoys a high ethnic "valence" will find it advantageous to compete for followers by spending more on military "protection" and, by so doing, succeed in expanding its political base. The spread of settlements on the West Bank; the fear of Hamas; the sense of danger that pervades the interior valleys of Colombia - each attests to the power of the incentives that generate the behavior captured by Result 7 .

Result 5 provides additional insight into the characteristics of political competition in the developing world.

Taken together, Results 5 and 7 help us to appreciate the nature of politics in weak states. When military resources substitute for public goods, then élites endowed with superior political loyalty will respond to a cost advantage in the procurement of military weapons not by reducing such expenditures but rather by seeking to outspend their rivals. When military resources offer complements for public goods, then the elite endowed with superior political loyalty will outspend its rival, even when possessing no cost advantage. Under the conditions outlined in Results 5 and 7 , then, to be militant, ethnically, is also to be militaristic, politically. Our findings thus underscore the links between sub-national loyalties, the militarization of politics, and the fragility of political order in developing societies.

\section{References}

Alesina, A. and E. Spolaore (1997), “On the number and size of nations”, Quarterly Journal of Economics, 1027-56.

Almond, G.A., and J.S. Coleman, eds. (1960), The Politics of the Developing Areas. Princeton NJ: Princeton University Press.

Anderson, C.W., F.R. von der Mehden, and F. Young (1967), Issues of Political Development. Englewood Cliffs NJ: Prentice-Hall.

Apter, D. (1963), "Political Religion in the New Nations", in Old Societies and New States, edited by D. Apter. New York: The Free Press of Glencoe.

Collier, P. and A. Hoeffler (1998), "On the economic causes of civil war", forthcoming in Oxford Economic Papers. 
Downs. A. (1957), An Economic Theory of Democracy, New York: Harper and Row.

Ellman, M. and L. Wantchekon (2000), "Platform divergence under the threat of political unrest", The Quarterly Journal of Economics, 115(2), 499-531.

Enelow, J.M. and M.J. Hinich (1982), "Nonspatial candidate characteristics and electoral competition", Journal of Politics, 44(1), 115-30. (1984), The Spatial Theory of Voting. New York: Cambridge University Press.

Epstein, A. L. (1958), Politics in an Urban African Community, Mancheter: Manchester University Press.

Erie, S. (1988), Rainbow's End, Berkeley and Los Angeles: University of California Press.

Evans, P., T. Skocpol, and D. Rueschmeyer (1985), Bringing the State Back In, Cambridge: Cambridge University Press.

Evans, P. (1995), Embedded Autonomy: States and Industrial Transformation, Princeton: Princeton University Press.

Geertz, C. (1963), “The Integrative Revolution: Primordial Sentiments and Civil Politics in the New States", in Old Societies and New States, edited by D. Apter. New York: The Free Press of Glencoe.

Grossman, H.I. (1997), "Make us a king: Anarchy, predation, and the state", NBER Working Paper 6289. and M. Kim (1995), "Swords or plowshares? A theory of the security of claims to property”, Journal of Political Economy, 103 (6), 1275-88.

Harrington, J.E. and G.D. Hess (1996), "A spatial theory of positive and negative campaigning", Games and Economic Behavior, 17, 209-29.

Hirshleifer, J. (1989), "Conflict and rent-seeking success functions: Ratio vs. difference models of relative success", Public Choice, 63, 101-12.

(1991), "The technology of conflict as an economic activity", American Economic Review Papers and Proceedings, 81(2), 130-4.

Huntington, S.P. (1968), Political Order in Changing Societies. New Haven and London: Yale University Press. 
Jackson, R.H., and C.G. Rosberg, (1982), Personal Rule in Black Africa. Berkeley and Los Angeles: University of California Press.

Lipset, S. M. (1959), Political Man, Garden City NY: Doubleday.

Marcouiller, D. and L. Young (1995), "The black hole of graft: The predatory state and the informal economy", American Economic Review, 85(3), 630-46.

Melson, R. and H. Wolpe (1970), "Modernization and the Politics of Communalism", American Political Science Review 44,4,1112.1130.

Migdal, J.S., A. Kohli, and V. Shu (1994), State Power and Social Forces, Cambridge: Cambridge University Press.

Perry, E. J. (1998), Shanghai on Strike, Stanford CA: Stanford University Press.

Persson, T. and G. Tabellini, (2000), Political Economics: Explaining Economic Policy. Cambridge: MIT Press.

Skaperdas, S. (1992), "Cooperation, conflict, and power in the absence of property rights", American Economic Review, 82, 720-39.

Weber, M. (1958), "Politics as a Vocation", in From Max Weber, edited by H. H. Gerth and C. W. Mills. New York: Oxford University Press. (1985), Basic Concepts in Sociology, Seacaucus NJ: Citadel Press. 


\section{Appendix}

\section{A.1 Proof of lemma 1}

By assumption (A6), $U\left(l, \lambda_{A}\right)>U\left(l, \lambda_{B}\right)$ when evaluated at $l=\lambda_{A}$, and $U\left(l, \lambda_{A}\right)<U\left(l, \lambda_{B}\right)$ when evaluated at $l=\lambda_{B}$. Continuity and monotonicity of $V(\cdot)$ guarantee that there exists a unique intermediate value $x \in\left(\lambda_{A}, \lambda_{B}\right)$ such that $U\left(x, \lambda_{A}\right)=U\left(x, \lambda_{B}\right)$ and that $U\left(l, \lambda_{A}\right)>U\left(l, \lambda_{B}\right)$ for all $l<x$ and $U\left(l, \lambda_{A}\right)<U\left(l, \lambda_{B}\right)$ for all $l>x$.

\section{A.2 Determinants of $x$}

Implicitly differentiating expression (5) yields:

(a1)

$$
\frac{\partial x}{\partial M}=\frac{G^{\prime}(M)}{V^{\prime}\left(x-\lambda_{A}\right)+V^{\prime}\left(\lambda_{B}-x\right)}>0
$$

$$
\frac{\partial x}{\partial m}=-\frac{g^{\prime}(m)}{V^{\prime}\left(x-\lambda_{A}\right)+V^{\prime}\left(\lambda_{B}-x\right)}<0
$$

$$
\frac{\partial x}{\partial \lambda_{A}}=\frac{V^{\prime}\left(x-\lambda_{A}\right)}{V^{\prime}\left(x-\lambda_{A}\right)+V^{\prime}\left(\lambda_{B}-x\right)}>0
$$

$$
\frac{\partial x}{\partial \lambda_{B}}=\frac{V^{\prime}\left(\lambda_{B}-x\right)}{V^{\prime}\left(x-\lambda_{A}\right)+V^{\prime}\left(\lambda_{B}-x\right)}>0
$$

\section{A.3 Equilibrium conditions}

Applying the Kuhn-Tucker theorem to problem (1) we get the first order conditions for competitor A:

(a7) $\quad\left[t x\left(\lambda_{A}, \lambda_{B}, M, m\right)-C\left(\lambda_{A}\right)-H(M)\right] \cdot \mu_{1}=0$ $\operatorname{tx}\left(\lambda_{A}, \lambda_{B}, M, m\right)-C\left(\lambda_{A}\right)-H(M) \geq 0, \mu_{1} \geq 0 \quad$ with complementary slackness

$$
\lambda_{A} \cdot \mu_{2}=0 \quad \lambda_{A} \geq 0, \quad \mu_{2} \geq 0 \quad \text { with complementary slackness }
$$




$$
\left(1-\lambda_{A}\right) \cdot \mu_{3}=0 \quad\left(1-\lambda_{A}\right) \geq 0, \quad \mu_{3} \geq 0
$$

$M \geq 0$,

$\mu_{4} \geq 0$

with

complementary

slackness

where $x$ is implicitly defined by (5) in the text and the partial derivatives in (a5) and (a6) are given by (a3) and (a1).

Similarly, the first order conditions for competitor B are:

$$
\left[-t \frac{\partial x}{\partial \lambda_{B}}-c^{\prime}\left(\lambda_{B}\right)\right]\left(1+v_{1}\right)-v_{2}=0
$$

$$
\left[-t \frac{\partial x}{\partial m}-h^{\prime}(m)\right]\left(1+v_{1}\right)+v_{3}=0
$$

$$
\left[t\left(1-x\left(\lambda_{A}, \lambda_{B}, M, m\right)\right)-c\left(\lambda_{B}\right)-h(m)\right] \cdot v_{1}=0
$$

$$
\left[t\left(1-x\left(\lambda_{A}, \lambda_{B}, M, m\right)\right)-c\left(\lambda_{B}\right)-h(m)\right] \geq 0, \quad v_{1} \geq 0 \quad \text { with complem. slackness }
$$

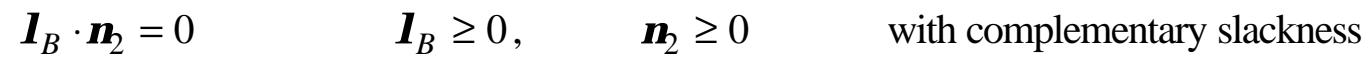

$$
\left(1-\lambda_{B}\right) \cdot v_{3}=0 \quad 1-\lambda_{B} \geq 0, \quad v_{3} \geq 0 \quad \text { with complementary slackness }
$$

$m \cdot v_{4}=0$

$$
m \geq 0,
$$$$
v_{4} \geq 0
$$

with complementary slackness

where $x$ is implicitly defined by (5) in the text and the partial derivatives in (a11) and (a12) are given by (a4) and (a2).

Equilibria type 1,2 and 3 in the text are obtained by setting respectively:

1) $\mu_{2}=\mu_{3}=v_{2}=v_{3}=0, \mu_{4}>0, v_{4}>0$;

2) $\mu_{2}>0, v_{3}>0, \mu_{3}=\mu_{4}=v_{2}=v_{4}=0$;

3) $\mu_{2}=\mu_{3}=\mu_{4}=v_{2}=v_{3}=v_{4}=0$.

Of course, depending on functional forms and parameter values many other combinations than 1)-3) are possible, including some in which one of the competitors uses one instrument only while the other uses both.

\section{A4. Proof of result 2}


When $c(\lambda)=C(1-\lambda)$, the right hand side of equation (10) in the text is $-C^{\prime}\left(1-\lambda_{B}{ }^{*}\right)$. Dividing (9) by (10) we obtain:

$$
\frac{V^{\prime}\left(x-\lambda_{A}{ }^{*}\right)}{V^{\prime}\left(x-\lambda_{B}{ }^{*}\right)}=\frac{C^{\prime}\left(\lambda_{A}{ }^{*}\right)}{C^{\prime}\left(1-\lambda_{B}{ }^{*}\right)} .
$$

By result 1 , we know $x-\lambda_{A}{ }^{*}>\lambda_{B}{ }^{*}-x$, which implies (together with the assumption that $V(\cdot)$ is convex) that the left hand side of (a15) is greater than 1 . Given the convexity of $C(\cdot)$, this requires $\lambda_{A}^{*}>1-\lambda_{B}^{*}$.

\section{A5. Proof of result 3}

$\underline{\text { Part }(a)}$. Suppose $M^{*} \neq m^{*}$, and w.l.o.g. $M^{*}>m^{*}$. Then assumption (A2) in the text implies that the right hand side of equation (18) is greater than 1, which in turn implies $G^{\prime}\left(M^{*}\right)>g^{\prime}\left(m^{*}\right)$. However, by (A5) $M^{*}>m^{*}$ implies $G^{\prime}\left(M^{*}\right)<g^{\prime}\left(m^{*}\right)$, a contradiction. A similar argument can be used to rule out $M^{*}<m^{*}$.

$\underline{\text { Part }(b)}$. Consider first $M^{*}=m^{*}$. Assumption $H(\cdot) \equiv h(\cdot)$ implies that the right hand side of equation (18) is equal to 1 , while $G^{\prime}(M)>g^{\prime}(m)$ for all $M=m$ implies that the left hand side is strictly greater than 1 , hence we have a contradiction.

Suppose next that $M^{*}<m^{*}$. Assumptions A2 and $H(\cdot) \equiv h(\cdot)$ imply that the right hand side of equation (18) is less than 1 . Note that if $G^{\prime}(M)>g^{\prime}(m)$ for all $M=m$, then $G^{\prime}(M)>g^{\prime}(m)$ also for all $M<m$ due to concavity of $G(\cdot)$ and $g(\cdot)$ by A5. This implies that the left hand side of (18) should be greater than 1 , contradicting the above.

Then only possibility is therefore $M>m$.

$\underline{\operatorname{Part}(c)}$. The proof is along the same lines of part (b).

If $M^{*}=m^{*}$, assumption $G(\cdot) \equiv g(\cdot)$ implies that the left hand side of equation (18) is equal to 1, which is inconsistent with the right hand side being less than 1 due to $H^{\prime}(M)<h^{\prime}(m)$.

If instead $M^{*}<m^{*}$, assumptions A5 and $G(\cdot) \equiv g(\cdot)$ imply that the left hand side of equation (18) is greater than 1 . Note that if $H^{\prime}(M)<h^{\prime}(m)$ for all $M=m$, then $H^{\prime}(M)<h^{\prime}(m)$ also for all $M<$ 
$m$ due to convexity of $H(\cdot)$ and $h(\cdot)$ by A2. This implies that the right hand side of (18) should be less than 1 , contradicting the above.

Then only possibility is therefore $M>m$.

\section{A.6 Proof of result 4}

Dividing (19) by (20) we obtain:

$$
\frac{V^{\prime}\left(x-\lambda_{A}^{*}\right)}{V^{\prime}\left(\lambda_{B}^{*}-x\right)}=-\frac{C^{\prime}\left(\lambda_{A}^{*}\right)}{c^{\prime}\left(\lambda_{B}^{*}\right)}
$$

Under the assumption stated in result 4, the right-hand side of this equation is less than 1 , which -coupled with $V^{\prime \prime}(\cdot)>0$-- implies $x-\lambda_{A}{ }^{*}<\lambda_{B}{ }^{*}-x$. Given that $\alpha_{A}>\alpha_{B}$ and that $G(\cdot) \equiv g(\cdot)$, in expression (23) this is only compatible with $g\left(m^{*}\right)>\mathrm{G}\left(M^{*}\right)$, i.e. $m^{*}>M^{*}$.

\section{A.7 Proof of result 5}

Dividing (21) by (22) we obtain equation (18) in the text, so $M^{*}>m^{*}$ can be proved as in result 3c.

But then $G\left(M^{*}\right)>g\left(m^{*}\right)$ which, jointly with $\alpha_{A}>\alpha_{B}$, requires $V\left(x-\lambda_{A}{ }^{*}\right)>V\left(\lambda_{B}{ }^{*}-x\right)$ in equation (23). Given that $V^{\prime}(\cdot)>0$, this in turn implies $\left|x-\lambda_{A}{ }^{*}\right|>\left|x-\lambda_{B}{ }^{*}\right|$.

\section{A.8 Proof of result $7^{28}$}

Start from a situation where both $M$ and $m$ equal 0 , so that $F(M)=f(m)=1$. Then the originally indifferent citizen will be located at $x_{0}$ implicitly defined by $\alpha_{A}-\alpha_{B}=V\left(x_{0}\right)-V\left(1-x_{0}\right)$. Given that $\alpha_{A}>\alpha_{B}, x_{0}>1 / 2$. Now consider what would happen if each competitor increased military spending to $k>0$. The newly indifferent citizen would be located at at $x_{k}$ implicitly defined by $\alpha_{A}-\alpha_{B}=f(k)\left[V\left(x_{k}\right)-V\left(1-x_{k}\right)\right]$, where $f(k)=F(k)<1$. Since $\alpha_{A}-\alpha_{B}$ has not changed, it

\footnotetext{
${ }^{28} \mathrm{We}$ are grateful to a referee for suggesting this proof.
} 
must be $V\left(x_{k}\right)-V\left(1-x_{k}\right)>V\left(x_{0}\right)-V\left(1-x_{0}\right)$, which implies $x_{\mathrm{k}}>x_{0}$. When both competitors increase military spending by the same amount, the location of the pivotal citizen moves to the right. Spending $k$ in military force cannot therefore be an equilibrium for both $\mathrm{A}$ and $\mathrm{B}$, because while having the same marginal costs --due to the assumption $H(\cdot)=h(\cdot)$-- they would be having different marginal benefits, hence one of the two would not be optimizing. In particular, A's marginal benefit is higher than B's, so A's intrinsic advantage allows him to sustain a higher level of military expenditure and to tax the majority of the population. 